\title{
The Relationship of Cyber-bullying and Academic Achievement, General Health, and Depression in Adolescents in Thailand
}

\section{Supawadee CHAROENWANIT}

\author{
Faculty of Nursing, Thammasat University, Pathum Thani 12121, Thailand
}

('Corresponding author's e-mail: supawadee.c@nurse.tu.ac.th)

Received: 1 June 2017, Revised: 11 February 2018, Accepted: 19 March 2018

\begin{abstract}
This descriptive study aimed to correlate cyber bullying with academic achievement, general health, and depression among adolescents in Thailand. The participants in the study were composed of 400 senior high school and vocational certificate students aged 14 to 20 years. The results revealed that onethird of the participants were found to have been bullied (39.0\%). Furthermore, cyberbullying was correlated with academic achievement, general health, and depression among adolescents with a statistical significance of $0.01(\mathrm{rpb}=0.858, \mathrm{p}<0.01 ; \mathrm{rpb}=0.584, \mathrm{p}<0.01 ; \mathrm{rpb}=0.532, \mathrm{p}<0.01)$. Based on the findings, the following recommendations are suggested. As cyberbullying can be seen as a significant factor correlated with academic achievement, general health, and depression among adolescents, all people involved (families, schools, communities, and society) need to have awareness of, and place importance on, protecting and caring for children in the use of online social media within proper boundaries. Beginning with families, parents should place importance on speaking with adolescents about the problems or issues confronted by them at home and in school, and they should know how to observe the positive and negative changes in behavior among adolescents in order to help them search for guidelines to provide suitable and timely help for them. Most importantly, adolescents should be taught to be aware of the positive and negative impacts of their cyberbullying actions.
\end{abstract}

Keywords: Cyberbullying, academic achievement in adolescents, general health, depression in adolescents

\section{Introduction}

The development of communication technology is continuous and far-reaching. The Internet has become a new mode of communication and has permeated every dimension of society by enabling everyone to access online communication through the use of various electronic equipment, such as tablets, smartphones, desktop and portable computers, etc. [1]. This equipment has the ability to perform multiple functions, such as storing photos, uploading videos, surfing the net, and voice and text chatting through various applications such as Facebook, Twitter, and Line, enabling adolescents to expand their online social networks [2]. These properties of communication technology have influenced and responded to the communication needs of the adolescent generation, and the use of this communication equipment and technology enables adolescents to express their identity, to create relationships among groups of friends, to develop sexual relationships and, unfortunately, to bully others [3].

The most common type of bullying among children and adolescents is physical bullying or fighting, which involves bigger and older children bullying younger children. In such cases, adults can clearly identify the victim because of the presence of physical symptoms. However, with the advent of communication technology, bullying can extend beyond the home, playground, and school, where bullying occurs in cyberspace among persons or groups of persons. It involves insulting other persons by posting rude comments, sending vulgar messages, video clips, and e-mails, using various websites or 
applications to cause pain and psychological distress. Cyberbullying is considered a type of violence against another person that can occur anywhere and at any time [4].

At present, the use of cyberspace to bully or threaten others with the intention to cause suffering, which results in stress or hurts the feelings of others, is escalating worldwide. The aforementioned action is called "cyberbullying" Cyberbullying is emerging in every corner of the world, and the consequence is an urgent issue requiring management and care by every party involved, because the aforementioned problems have taken the lives of many children and adolescents across the globe. According to a global survey on the extent of the problems, the prevalence of cyberbullying is encountered at 20 to 40 percent $[5,6]$. A study conducted by the National Children's Bureau revealed that one out of 5 children and adolescents aged 10 to 19 years in England to be affected by cyberbullying. Furthermore, more young women were found to be victims of violence than young men. According to a study carried out by the Chinese University of Hong Kong, one out of 3 students was found to have been a victim of cyberbullying. In Thailand, a study by Musikpan, Pokpong, Songsiri, and Surut [7] surveyed cyberbullying behaviors among adolescents in the Bangkok area and found that a relatively high percentage of participants $(43.9 \%$ ) admitted to having been victims of cyberbullying. The type of bullying most frequently carried out was bullying by gossiping and insulting one another in cyberspace. According to a study by Dehue et al. [5], who studied cyberbullying among young female Thai adolescents, the above-mentioned group was found to have been victims of cyberbullying (45.4\%), divided according to online attacks and threats (41.4\%), online sexual threats (5.3), and harmful online information records and dissemination $(16.3 \%)$.

Based on the above-mentioned data, the trend of cyberbullying is obviously escalating worldwide. To make matters worse, many children and adolescents view cyberbullying as a normal action to which everyone is entitled [7].

In the past, many researchers studied the effects of cyberbullying and found that it causes many problems. Examples of these problems include academic achievement problems, such as school absenteeism, skipping classes, and low achievement; emotional problems, such as anxiety, loneliness, sadness, depression, insecurity, low self-esteem, or even suicide; and behavioral problems, such as aggression, violence, substance abuse behaviors, etc. [8-12]. This is evident from a study by Schenk et al. [13], who studied the prevalence of psychological impacts and impact management by students that were victims of cyberbullying, and found that the students that were victims of cyberbullying had more depression, anxiety, and paranoia than the non-victim group, with a statistical significance of $(\mathrm{p}<0.05)$. Furthermore, a study by Perren, and Eveline [10], who studied the correlations between cyberbullying and depression in adolescents, found that the participants that were victims of cyberbullying had a higher degree of depression than the participants that were not victims of cyberbullying. Moreover, cyberbullying was correlated with depression at a statistical significance of $(p<0.01)$. In addition, Robin and Susan [11], who studied the correlations among cyberbullying, mental health problems, physical health problems, and academic achievement problems of adolescents, found that the participants that were victims of cyberbullying had high anxiety and depression scores. Moreover, the victims of cyberbullying also had more physical health problems and lower academic achievement than the participants that were not victims of cyberbullying. When the differences between young men and young women were compared, the young women were found to have higher scores for anxiety, depression, and health problems than the young men.

Nevertheless, the data were only partially reflected the problems or the impacts that occurred from cyberbullying in adolescents. Most of these studies focused on adolescents' attitudes toward cyberbullying, rather than the impacts of cyberbullying. The problems and impacts from cyberbullying, such as physical health problems, academic achievement problems, and mental health problems, such as depression or, most severely, suicide problems, are of course of concern for adolescents. In the present study, therefore, the researcher is interested in studying the correlations among cyberbullying and academic achievement, general health, and depression among adolescents, in order to perceive the problems from cyberbullying in Thai society more clearly and to create guidelines to prevent problems and to develop therapy programs to treat persons affected by cyberbullying in the future. 
http://wjst.wu.ac.th

\section{Questions}

Is cyberbullying correlated with academic achievement, general health, and depression among Thai adolescents?

What is the point of view of cyberbullying of Thai adolescents?

\section{Objective of the Study}

To study the correlations among cyberbullying and academic achievement, general health, and depression among Thai adolescents.

\section{Hypothesis}

Cyberbullying is correlated with academic achievement, general health, and depression among Thai adolescents.

\section{Materials and methods}

\section{Methodology}

This study was based on a descriptive research design, aimed at investigating the correlations among the cyberbullying, academic achievement, general health, and depression of 400 adolescents at 4 senior high schools located in 4 regions of Thailand (Nakhon Sawan, Nakhon Ratchasima, Lopburi, and Nakhon Si Thammarat), and at vocational education levels at 4 vocational schools located in the same 4 regions. These high schools and education facilities are under the jurisdiction of the Office of the Vocational Education Commission, Thailand. Data were collected from February 2016 to March 2016.

\section{Materials}

The instrumentation employed in the present study was composed of questionnaires with 3 parts, as described below.

The Sociodemographic Data Interview Form is a questionnaire created by the researcher, with 13 multiple choice and fill-in-the-blank questions on gender, age, level of education, cumulative GPA, family financial status, parents' marital status, parents' occupation, bullying or victim experience, types of bullying or victimization, and behaviors in skipping classes.

The General Health Questionnaire (GHQ-28) is a form of mental health disorder screening created by the Department of Mental Health, Ministry of Public Health in Thailand [14]. The questionnaire has a score cut-off point of 5/6. The questionnaire is composed of 28 questions, divided into 4 parts, consisting of 1) physical symptoms, 2) anxiety and insomnia problems, 3) social dysfunction and 4) severe depression symptoms. The instrument reliability was obtained by using Cronbach's alpha coefficient. The instrument was tested with 30 adolescents with qualifications similar to those in the participant group and had a Cronbach's alpha coefficient of 0.90. Moreover, the GHQ-28 Thai version was validated for its validity coefficients, resulting in sensitivity at 86 and specificity at 76 .

The Thai version of the Center for Epidemiologic Studies-Depression Scale (CES-D) was developed by Trangkasombat [15], who translated the scale into Thai. This CES-D test type is widely used to assess depression among adolescents. Scoring is based on depression violence or frequency, with 4 levels, consisting of $0-3$ points when all answers are collected and compared to the normal criteria as follows: a total score higher than 22 points means that the respondent has depression. Instrument reliability was obtained at 0.78 for 30 adolescents with qualifications similar to those in the participant group. Moreover, the CES-D Thai version was validated for its validity coefficients, resulting in sensitivity at 78.8 and specificity at 91.3 .

\section{Data collection}

The researcher proposed the research project and requested certification from the Institutional Review Board at Thammasat University. Then, the researcher requested a letter from the Faculty of 
http://wjst.wu.ac.th

Nursing, Thammasat University, to be presented to the school and vocational college directors to explain the research objectives, to request cooperation in the study, and to obtain permission to collect data. After the schools granted permission, the researcher met with the schools' guidance instructors to introduce herself and to explain the research objectives, plans, data collection, instrumentation, and protection of the rights of the participants, in order to request cooperation in the study. The researcher sent the informed consent letters and questionnaires to the instructors. This study was carried out correctly based on human research ethics, and approximately 15 to $20 \mathrm{~min}$ were spent in completing the questionnaires.

\section{Data analysis}

A computer program package was used to analyze the data by using frequency distribution, percentage, mean, and standard deviation to analyze the sociodemographic factors, academic achievement, and general health and depression among adolescents, while the Point Biserial Correlation Coefficients were used to test the correlations among cyberbullying and academic achievement, general health, and the depression of adolescents.

\section{Results and discussion}

\section{Part 1: Sociodemographic data of the participants Population characteristics}

The participant group for this study was composed of 400 participants, with 202 young male participants $(50.5 \%)$ and 198 young female participants $(49.5 \%)$. The participants had a mean age of 16.99 years $($ Mean $=16.99$, S.D. $=1.03)$. Some of the participants $(75.0 \%)$ lived with their parents $(300$ participants). Thirty percent of participant's parent working as hired workers. The participants $(55.0 \%$ or 220 participants) had an overall family income of 91.60- 458.02 USD per month, as shown in Table 1.

According to Table 2, the participants were divided into 4 groups, with 138 participants $(34.5 \%)$ in the group of persons that were both victims and bullies, 18 participants $(4.5 \%)$ in the victim group, and 244 participants $(61 \%)$ in the group of persons that were non-bullies and non-victims.

According to Tables 3 and 4, the 3 modes most frequently used to bully the participants consisted of Facebook (36.5\%) (146 participants), You tube (29.5\%) (118 participants), and LINE (25.0\%) (100 participants), while the 3 types or characteristics of cyberbullying most frequently encountered by the participants were composed of lies created to cause dislike by others (36.5\%) (146 participants), followed by bullying via damaging audio or video clips (36.0\%) (144 participants), and harassing text messages (34.0\%) (136 participants).

According to Tables 5 and 6, the 3 modes of bullying most frequently used by the participants to bully others were as follows: 1) Facebook (32.0\%) (128 participants), 2) You tube (32.0\%) (128 participants), and 3) LINE (25.0\%) (100 participants). At the same time, the 3 most frequentlyencountered types or characteristics of bullying were: 1$)$ lies created to cause dislike by others $(36.5 \%)$ (146 participants), 2) harassing text messages (35.0\%) (140 participants), and 3) damaging audio or video clips (34.5\%) (138 participants).

According to Table 7, one-third of the participants considered cyberbullying appropriate, and the opinions of the participants that believed that cyberbullying was appropriate can be divided into the following 3 main groups.

Group 1 viewed cyberbullying as normal: cyberbullying is normal and can be done by anyone. The participants did not see anything strange about cyberbullying. Many stars, actors, or famous persons that are victims of cyberbullying have gained fame this way.

Group 2 considered cyberbullying to be the most appropriate method for letting others know about bad friends: posting bad information or messages belonging to others lets other people know that a person is bad. Audio or video clips will help others more clearly witness how bad the person is.

Group 3 considered cyberbullying to be the most appropriate method of revenge. In other words, since others can vilify a person with either true or false stories, the same can be done to those people.

According to Table 7, the participants that viewed the use of online social media to bully others as inappropriate can be divided into the following 2 groups. 
http://wjst.wu.ac.th

Table 1 Sociodemographic data $(\mathrm{N}=400)$.

\begin{tabular}{|c|c|c|}
\hline Sociodemographic data & Number (n) & Percent (\%) \\
\hline \multicolumn{3}{|l|}{ Gender } \\
\hline Female & 198 & 49.5 \\
\hline Male & 202 & 50.5 \\
\hline \multicolumn{3}{|l|}{ Age (Years) } \\
\hline $14-17$ (Mid-adolescence) & 284 & 71.0 \\
\hline $18-20$ (Late adolescence) & 116 & 29.0 \\
\hline \multicolumn{3}{|l|}{ Level of education } \\
\hline Senior high school & 200 & 50.0 \\
\hline Grade 10 & 68 & 17.0 \\
\hline Grade 11 & 66 & 16.5 \\
\hline Grade 12 & 66 & 16.5 \\
\hline Vocational education & 200 & 50.0 \\
\hline Vocational education 1 & 66 & 16.5 \\
\hline Vocational education 2 & 66 & 16.5 \\
\hline Vocational education 3 & 68 & 17.0 \\
\hline \multicolumn{3}{|l|}{ Overall family income USD (Monthly) } \\
\hline $91.60-458.02$ & 220 & 55.0 \\
\hline $458.05-916.03$ & 86 & 21.5 \\
\hline $916.06-1,374.05$ & 34 & 8.50 \\
\hline $1,374.08-1,832.06$ & 40 & 10.0 \\
\hline $1,832.09-2,290.08$ & 16 & 4.0 \\
\hline 2,290.11-2,748.09 & 2 & 0.5 \\
\hline More than 2,748.09 & 2 & 0.5 \\
\hline \multicolumn{3}{|l|}{ Parents' marital status } \\
\hline Married & 316 & 79.0 \\
\hline Divorced & 62 & 15.5 \\
\hline One deceased parent & 22 & 5.5 \\
\hline \multicolumn{3}{|l|}{ Characteristics of family } \\
\hline Parents & 300 & 75.0 \\
\hline Father & 16 & 4.0 \\
\hline Mother & 35 & 8.0 \\
\hline Grandparents & 36 & 9.0 \\
\hline Uncles/Aunts & 16 & 4.0 \\
\hline \multicolumn{3}{|l|}{ Parents' occupation } \\
\hline Hired worker & 120 & 30.0 \\
\hline Farmer & 86 & 21.5 \\
\hline Private company & 72 & 18.0 \\
\hline Trader & 62 & 15.5 \\
\hline Civil service/Government enterprise & 60 & 15.0 \\
\hline
\end{tabular}


http://wjst.wu.ac.th

Table 2 Number and percentage of the samples divided by group.

\begin{tabular}{lcc}
\hline & Number (n) & Percent (\%) \\
\hline The group of persons that were both victims and bullies & 138 & 34.5 \\
The victim group & 18 & 4.5 \\
The bully group & 0 & 0 \\
The group of persons that were both non-bullies and non-victims & 244 & 61.0 \\
\hline
\end{tabular}

Table 3 Number and percentage of the samples divided by types or characteristics or mode of cyberbullying $(\mathrm{N}=400)$.

\begin{tabular}{lcccc}
\hline \multirow{2}{*}{ Bullying mode } & \multicolumn{2}{c}{ Groups were bullied via this mode } & \multicolumn{2}{c}{ Groups were not bullied via this mode } \\
\cline { 2 - 5 } & Number (n) & Percent (\%) & Number (n) & Percent (\%) \\
\hline Email & 20 & 5.0 & 380 & 95.0 \\
Mobile phone text messages & 32 & 8.0 & 368 & 92.0 \\
LINE & 100 & 25.0 & 300 & 75.0 \\
Facebook & 146 & 36.5 & 254 & 63.5 \\
Twitter & 18 & 4.5 & 382 & 95.5 \\
You tube & 118 & 29.5 & 282 & 70.5 \\
\hline
\end{tabular}

Table 4 Number and percentage of samples divided by types of bullying encountered by the samples.

\begin{tabular}{lcccc}
\hline \multirow{2}{*}{ Type or characteristic } & \multicolumn{2}{c}{ Groups were bullied by this type } & \multicolumn{2}{c}{ Groups were not bullied by this type } \\
\cline { 2 - 5 } & Number (n) & Percent (\%) & Number (n) & Percent (\%) \\
\hline Harassing text messages & 136 & 34.0 & 264 & 66.4 \\
Framed by creating damaging rumors & 90 & 22.5 & 300 & 77.5 \\
Lies created to cause dislike by others & 146 & 36.5 & 254 & 63.5 \\
Damaging audio or video clips & 144 & 36.0 & 256 & 64.0 \\
\hline
\end{tabular}

Group 1 believed in personal rights: every person should respect their own rights and the rights of others. Negative stories about others should not be posted, and false opinions causing damage to others should not be expressed.

Group 2 considered cyberbullying to create a stigma: the fact that a person creates lies or posts audio or video clips of others on online social media creates a stigma for that person, because those audio or video clips and messages will remain on online social media for a long time. The consequence is shame for that person.

Part 2: Results from the analysis of the correlations among cyberbullying and academic achievement, general health, and the depression of adolescents

When the correlations among cyberbullying and academic achievement, general health, and the depression of adolescents were studied, cyberbullying was found to be highly and positively correlated with academic achievement, with a statistical significance of $0.01(\mathrm{rpb}=0.858, \mathrm{p}<0.01)$. According to the interpretation, the participants that were victims or cyberbullies had high academic achievement problems. Furthermore, cyberbullying was positively correlated with general health and depression 
http://wjst.wu.ac.th

among adolescents to a moderate degree and at a statistical significance of $.01(\mathrm{rpb}=0.584, \mathrm{p}<0.01 ; \mathrm{rpb}$ $=0.532, \mathrm{p}<0.01)$. Hence, the participants that were victims or cyberbullies had greater general health and depression problems, as shown in Table 10.

Table 5 Number and percentage of samples divided by types of cyberbullying used to bully others $(\mathrm{N}=$ 400).

\begin{tabular}{lcccc}
\hline \multirow{2}{*}{ Types } & \multicolumn{2}{c}{ Group of individuals that bullied others } & \multicolumn{2}{c}{ Group of individuals that did not bully } \\
\cline { 2 - 5 } & Number (n) & Percent (\%) & Number (n) & Percent (\%) \\
\hline Email & 18 & 4.5 & 382 & 95.5 \\
Mobile Phone Messages & 30 & 7.5 & 370 & 92.5 \\
LINE & 100 & 25.0 & 300 & 75.0 \\
Facebook & 128 & 32.0 & 272 & 68.0 \\
Twitter & 18 & 4.5 & 382 & 95.5 \\
YouTube & 128 & 32.0 & 272 & 68.0 \\
\hline
\end{tabular}

Table 6 Numbers and percentages of samples divided by types or characteristics of cyberbullying.

\begin{tabular}{lcccc}
\hline \multirow{2}{*}{ Types or characteristic } & \multicolumn{2}{c}{ Group of individuals that bullied others } & \multicolumn{2}{c}{ Group of individuals that did not bully } \\
\cline { 2 - 5 } & Number (n) & Percent (\%) & Number (n) & Percent (\%) \\
\hline Harassing text messages & 140 & 35.0 & 260 & 65.0 \\
Framed by creating damaging rumors & 10 & 25.0 & 300 & 75.0 \\
Lies created to cause dislike by others & 146 & 36.5 & 254 & 63.5 \\
Damaging audio or video clips & 138 & 34.5 & 262 & 65.5 \\
\hline
\end{tabular}

Table 7 Numbers and percentages of samples divided by opinions of the samples on the use of online social media to bully others $(\mathrm{N}=400)$.

\begin{tabular}{lcc}
\hline Opinion & Number (n) & Percent (\%) \\
\hline Appropriate & 138 & 34.5 \\
Inappropriate & 262 & 65.5 \\
\hline
\end{tabular}

Table 8 Scoring range, minimum and maximum scores, mean, and standard deviation of general health scores.

\begin{tabular}{lcccc}
\hline General health & $\begin{array}{c}\text { Normal scoring } \\
\text { range }\end{array}$ & $\begin{array}{c}\text { Mean score from } \\
\text { the victim group }\end{array}$ & $\begin{array}{c}\text { Mean score from the } \\
\text { bully/victim group }\end{array}$ & $\begin{array}{c}\text { Mean score from the non- } \\
\text { bully/non-victim group }\end{array}$ \\
\hline Total general health score & $0-28$ & 12 & 10 & 5.6 \\
- Somatic symptoms & $0-7$ & 4 & 2 & 2.3 \\
- Anxiety and insomnia & $0-7$ & 4 & 3 & 1.2 \\
- Social dysfunction & $0-7$ & 4 & 2 & 1 \\
- Severe depression & $0-7$ & 4 & 3 & 1 \\
\hline
\end{tabular}


http://wjst.wu.ac.th

Table 9 Score range, minimum and maximum scores, mean, and standard deviation of general health scores.

\begin{tabular}{lcccc}
\hline Depression & $\begin{array}{c}\text { Normal scoring } \\
\text { range }\end{array}$ & $\begin{array}{c}\text { Mean score from } \\
\text { the victim group }\end{array}$ & $\begin{array}{c}\text { Mean score from the } \\
\text { bully/victim group }\end{array}$ & $\begin{array}{c}\text { Mean score from the non- } \\
\text { bully/non-victim group }\end{array}$ \\
\hline $\begin{array}{l}\text { Total Depression Score } \\
\text { among Adolescents }\end{array}$ & $0-60$ & 22 & 27.78 & 20.63 \\
\hline
\end{tabular}

Table 10 Correlations among cyberbullying, academic achievement, general health, and depression.

\begin{tabular}{lll}
\hline & \multicolumn{1}{c}{ Studied variable } & Cyberbullying \\
\hline 1. & Academic achievement & $\mathrm{r}_{\mathrm{pb}}=0.858^{* *}$ \\
2. & General health & $\mathrm{r}_{\mathrm{pb}}=0.584^{* *}$ \\
3. & Depression & $\mathrm{r}_{\mathrm{pb}}=0.532^{* *}$ \\
\hline
\end{tabular}

$* p<0.05, * * p<0.01$

$\mathrm{r}_{\mathrm{pb}}=$ Point Biserial Correlation Coefficients

\section{Discussion of the findings}

Part 1: Sociodemographic data on the adolescents

Sociodemographic data

Adolescence is a time of increasing vulnerability in terms of finding a balance between autonomy and connectedness. The Internet and social network systems provide new contexts for reflecting on and trying out new identities, for learning and attempting new social skills, and for establishing affiliations. Moreover, several studies have shown that mid-adolescence is the time when youths spend most of their time on the Internet and use social network systems [11,17]. Further, based on a survey by Emarket.com from a study of online social networks worldwide on the 3 online social media modes most popularly used by adolescents (Facebook, Google, and YouTube), the reason offered was that all of the aforementioned modes were easily accessed and open to allow everyone the opportunity to express his or her opinions. In Thailand, surveys have found the 3 online social media modes most popularly used by adolescents to be Facebook, Google, and LINE. These findings concur with the present study, which found that Facebook, YouTube, and LINE to be the modes most frequently used by the participants to cyberbully others, or the modes through which the participants were cyberbullied. Furthermore, when the types or characteristics of bullying encountered or used in cyberbullying were considered, the findings were found to be concurrent with the study by Samoh et al. [16], who studied the adolescent perceptions of cyberbullying. According to the findings, the types and characteristics of cyberbullying were composed of attacks or the use of insulting language via the Internet in various forums, online sexual threats by sending images or video clips to cause unwanted shame for the recipient, impersonating others to create damage and hate in various forms, blackmailing, for example, by disclosing or modifying personal information or secret information belonging to others, or the creation of online social networks to attack disliked persons.

\section{Academic achievement}

Based on the findings of the present study, when the data on mean academic achievements were compared in each group, the bully/victim group or the victim group was found to have lower academic achievement after being cyberbullied or after cyberbullying than before being cyberbullied or after 
cyberbullying, while the non-victim/non-bully group had higher mean academic achievement at a statistical significance of $(\mathrm{t}=14.027, \mathrm{p}=0.05 ; \mathrm{t}=11.050, \mathrm{p}=0.05 ; \mathrm{t}=-6.474, \mathrm{p}=0.05)$. In addition to low academic achievement, another important problem among the victim group was skipping classes or refusing to go to school. The findings revealed the bully/victim group to have a history of skipping classes, or refusing to go to school, at a level as high as $79.7 \%$, while the participants that were never bullied and that never bullied others had no problems with refusing to go to school. The aforementioned findings were consistent with the previous findings of Robin and Susan [11], who studied the correlations among cyberbullying and mental health problems, physical health problems, and educational problems among adolescents. The findings revealed the victim group to have lower academic achievement than the group that was never bullied. The fact that the academic achievement of the victim group was lower may be due to the fact that the cyberbullying caused the participants to be ashamed, to not want to meet people, and to be unable to see or unable to listen to criticism of themselves. Thus, the participants decided to refuse to go to school. Lower academic achievement represented severe consequences.

\section{General health and depression among adolescents}

According to the findings, the participants in the victim/bully group were found to have more problems regarding general health and depression than the non-victim and non-bully groups. This was because cyberbullying actions of any type will at least impact adolescents in the areas of physical or mental health, especially concerning emotional and psychological impacts, because cyberbullying causes adolescents to feel annoyed, bored, and undervalued, as the above-mentioned actions threaten the adolescents' personal space. Cyberbullying, in particular, causes symptoms to be more severe, because adolescents can become victims or bullies anywhere. Therefore, the impact is more severe than with other types of bullying among adolescents, because the adolescents frequently have no place to avoid cyberbullying by others, even in the adolescents' own bedrooms. The aforesaid problem has multiple negative effects, such as stress, anxiety, eating disorders, sleeping disorders, or problems in daily life, where adolescents have to hide from others or avoid questions from others about events encountered by them in cyberspace. Most severely, the adolescents that are unable to manage their problems are at risk of eventually committing suicide. The findings from this study concurred with the previous findings of Schenk et al. [13], who studied the prevalence of the psychological effects and the management of effects by students that were victims, and found that students that were victims were more depressed, anxious, and paranoid than the non-victim group, with a statistical significance of $(p<0.05)$. Additionally, according to Perren and Eveline [10], who studied the relationship between cyberbullying and depression among adolescents, the participants in the victim group were found to have greater depression than the non-victim group, and cyberbullying was found to be correlated with depression at a statistical significance of $(p<0.01)$. Robin and Susan [11] studied the correlations among cyberbullying, mental health problems, physical health problems, and academic achievement problems among adolescents, and found the participants in the victim group to have high anxiety and depression scores. Furthermore, the victim group also had more physical health problems than the non-victim group. When the differences between young men and young women were compared, the young women were found to have higher scores for anxiety and depression than the young men.

Part 2: Discussion of the findings based on the hypothesis

Hypothesis: cyberbullying is correlated with academic achievement, general health, and depression among Thai adolescents.

The findings from studying the correlations among cyberbullying and academic achievement, general health, and depression among Thai adolescents revealed cyberbullying to be positively correlated with academic achievement to a high degree and with a statistical significance of $0.01(\mathrm{rpb}=0.858, \mathrm{p}<$ 0.01). Thus, the participants in the bully/victim group had high academic achievement problems. Furthermore, cyberbullying was found to be positively correlated with general health and depression to a moderate degree, with a statistical significance of $0.01(\mathrm{rpb}=0.584, \mathrm{p}<0.01 ; \mathrm{rpb}=0.532, \mathrm{p}<0.01)$. Thus, the participants in the bully/victim group had higher degrees of general health and depression 
problems. The findings of this study reaffirm the obvious severity of the effects and problems from cyberbullying among adolescents in the victim/bully group, ranging from minimal effects such as low academic achievement problems to physical and mental health problems. The problems of greatest concern are depression and potential suicide. The findings from the present study concur with other studies concerning the effects of cyberbullying, and found cyberbullying to cause many other negative effects, such as academic problems, emotional problems, behavioral problems and substance abuse, etc. [8-12]. For example, Schenk et al. [13 ], who studied the prevalence of mental impacts and the management of these impacts by students in the victim group, found that students that were victims of cyberbullying had a higher prevalence of depression, anxiety, and paranoia than the non-victim group, with a statistical significance of $(p<0.05)$. According to a study of Perren and Eveline [10], who studied the correlations between cyberbullying and depression among adolescents, the participants in the victim group had a higher prevalence of depression than the non-victim group, and cyberbullying was found to be correlated with depression with a statistical significance of $(p<0.01)$. In addition, Robin and Susan [11] studied the relationships among cyberbullying, mental health problems, physical health problems, and academic achievement problems among adolescents, and found the participants in the victim group to have high anxiety and depression scores. Furthermore, the victim group also had more physical health problems and lower academic achievement than the non-victim group.

\section{Conclusions}

\section{Limitations of the study}

One of the most important factors that the researcher has to consider is the frequency and duration of the cyberbullying that the participants have to face, because these factors can help one see the obvious severity of the correlations among cyberbullying and the physical and mental health problems of adolescents; however, this study did not discuss these factors. Therefore, in future study, these factors should also be of concern.

\section{Recommendations}

Recommendations for implementing the findings

According to the findings, cyberbullying is an important factor correlated with academic achievement, general health, and depression in adolescents. Therefore, the people involved with adolescents, such as families, schools, communities, and society, should be aware of, and give importance to, prevention and care, in order to ensure that children use online social media within proper boundaries. Beginning with families, parents should give importance to the issue of discussing problems or issues confronted by adolescents at home and at school. Parents need to know how to observe the positive and negative changes in adolescents' behaviors in order to seek suitable guidelines for helping them in time. Most importantly, children and adolescents should be taught to recognize and be aware of the consequences of their actions before doing anything in cyberspace.

\section{Recommendations for future studies}

Experimental studies should be conducted by creating programs with the objective of reducing cyberspace utilization behaviors among adolescents. Further, proper knowledge about the impact of the actions of adolescents and raising the awareness of parents and teachers to recognize potential problems or impacts from cyberbullying to better reduce potential problems from the use of cyberspace by adolescents should promoted.

\section{Acknowledgements}

The author would like to acknowledge the Faculty of Nursing, Thammasat University, for funding this research project, and the Research Center of Nursing and Behavioral Science, Faculty of Nursing, Thammasat University, for assisting the author with the publication. 
http://wjst.wu.ac.th

\section{References}

[1] J Donner. Research approaches mobile use in the developing world: A review of the literature. Inform. Soc. 2010; 24, 140-59.

[2] P Saipradit. Internet Users in Providing Integrated Media. Available at: http://www.nectec.or.th. accessed January 2015.

[3] P Boonmongkon, R Iaumsrie, S Tounpananan, T Ojanen, R Samakkeekarum, R Samua, R Shunrun, $\mathrm{T}$ Guadamuz and Payukkakom. Gender, Sexuality, and cyberbullying of teen girls in Thailand. In: Proceeding of the Conference on Health Sciences 2012. Mahidol University, Bangkok, Thailand.

[4] S Shariff. Cyberbullying: Issues and solutions for the school, the classroom, and the home. Oxon, Routledge, UK, 2008.

[5] F Dehue, B Catherine and Trijntje. Cyberbullying: Youngsters' experiences and parental perception. Cyberpsychol. Behav. 2008; 11, 217-23.

[6] RS Tokunaga. Following you home from school: A critical review and synthesis of research on cyberbullying victimization. Comput. Human. Behav. 2010; 26, 277-87.

[7] W Musikpan, S Pokpong, N Songsiri and P Surut. Cyberbullying Behavior of Adolescent in Bangkok Thailand. The Wisdom Society for Public Opinion Research of Thailand, Bangkok, Thailand, 2009.

[8] S Bauman, R Toomey and J Walker. Associations among bullying, cyberbullying, and suicide in high school students. J. Adolesc. 2013; 36, 341-50.

[9] C Helen. Cyberbullying and its impact on young people's emotional health and well-being. Psychiat. 2013; 37, 167-70.

[10] S Perren and GH Eveline. Cyberbullying and traditional bullying in adolescence: Differential roles of moral disengagement, moral emotions, and moral values. Eur. J. Dev. Psychol. 2010; 9, 195-209.

[11] MK Robin and PL Susan. Psychological, physical, and academic correlates of cyberbullying and traditional bullying. J. Adolesc. Health 2013; 53, s13-s20.

[12] O Rosario, E Paz, AM Joaquin, G Luisa, B Antonella, G Annalisa, KS Peter, T Fran and T Neil. The emotional impact of bullying and cyberbullying on victims: A European cross-national study. Aggress. Behav. 2012; 38, 342-56.

[13] AM Schenk, WJ Fremouw and CM Keelan. Characteristics of college cyberbullies. Comput. Human. Behav. 2012; 29, 2320-7.

[14] T Nilchaikovit, C Sukying and C Silpakit. The Project of Preparing a Program to Explore Mental Health in the Area in 1992. Department of Mental Health, Ministry of Public Health, Thailand, 1992.

[15] U Trangkasombat and D Likanapichitkul. The children's depression inventory as a screen for depression in Thai children. J. Med Assoc. Thailand 1997; 80, 491-9.

[16] N Samoh, P Boonmongkon, T Ojanen, R Samkkeekarom and T Guadamuz. Youth perceptions on cyberbullying. J. Behav. Sci. Develop. 2014; 6, 351-63.

[17] M Price and J Dalgleish. Cyberbullying experiences, impacts and coping strategies as described by Australian young people. Youth Stud. Aust. 2010; 29, 51-9. 